\title{
A Survey in a Thai Classroom on Learning Activities and Learning Problems
}

\author{
Saranya Saetang \\ Kasetsart University, Sakon Nakhon Campus, Thailand
}

\begin{abstract}
To identify an appropriate learning approach, particularly for Thai students, this paper surveyed a preferred learning activities and problems that students faced in a classroom. The forty one students from the information technology department were selected as convenient samples to respond to the open-ended questions. The results were analyzed from students' preferred activities by using content analysis. It was found that students prefer a teachercentered approach with a discussion session to a student-centered approach. The greatest problem that students faced in a classroom caused by student ability was shyness to ask a question or speak up. Finally, the paper suggests that Thai culture and students 'disciplines are significant factors influencing the ways students decide their preferred learning approach and activity. Moreover, the flipped classroom could be a powerful technique applied in a lecture class to enhance learning performance for Thai students because it could help lecturers manage their time with their students.
\end{abstract}

\section{Introduction}

Many studies have been conducted to find the best learning approach and learning style to improve student performance. The starting point of this study is the attempt to find an appropriate learning approach for Thai students in the Management Information Systems lecture of Information Technology department of Kasetsart University (Chalermphrakiat Sakon Nakhon Province Campus), Thailand. It is to be hoped that students will improve learning performance and have a better study atmosphere. Moreover, the findings could be applied to other similar course content.

However, little research has been done in this area. Therefore, this study was conducted to search for an appropriate learning approach by examining the preferred class activities and obstacles that students encountered while attending a lecture. The two research questions were set accordingly. The questions are:

1. What are learning activities that students prefer in a lecture class?

2. What are problems that students faced in a lecture class?
The paper starts by reviewing the studies related to learning approach and Thai culture. Moreover, research methodology, results and discussions are clarified. Finally, some implications, conclusions and limitations are presented.

\section{Learning approach}

There are two main learning approaches that have been referred to by many researchers. One is the teacher-centered approach and the other is the student-centered approach [1].

The definition of the teacher-centered approach that will be applied in this paper is a traditional classroom where lecturers have the main role in leading a class and students passively receive knowledge.

In contrast to the teacher-centered classroom, the student-centered approach is a class that focuses on creating a learning environment where knowledge is shared by both lecturers and students rather than given by lecturers. That is students actively participate to the classroom and learn together with their lecturers [2].

The student-centered approach is quite difficult to implement in a Thai classroom because of the students' character which is likely to be influenced by Thai culture.

The next section will describe Thai culture and its characteristics which were suggested to influence Thais' attitudes and behaviors.

\section{Thai culture}

Previous work [3, 4] suggests that culture determines human decisions, action and behaviors. Thus, this study suggests that Thai students prefer a certain learning approach and activity due to cultural background.

Thai culture can be described as having an authoritarian structure, emphasizing collectivism, having significant emotional value and focusing on public achievements, avoiding embarrassment and focusing on a long-term vision [3].

The 'authoritarian structure' describes Thai culture in the sense that all work is led by a senior who is respected by younger members. Therefore, decisions are made at the top and formal processes and protocol are very important. 
With respect to 'collectivism', Thai people tend to focus more on collective goals, social relationships and social benefits.

With respect to 'emotional value', Thai culture emphasizes feelings and relationships including saving and giving face. Thai people prefer compromising to resolve conflict.

With respect to 'avoiding embarrassment and a strong long-term vision', Thais are moderately comfortable in dealing with uncertainty. They are tolerant of deviation. Some changes and adjustments are acceptable.

Furthermore, they are concerned about long-term relationships [3, 5]. Therefore, when Thai people meet someone for the first time, they will not speak up or express their feelings too much until they feel more familiar or comfortable with that person; they will be more open up and speak out their ideas and opinions. If the relationships with Thai people are built, it will continue for a long time.

\section{Academic disciplines and learning style}

Previous studies $[6,7]$ show that group characters such as academic disciplines affect learning styles. Students in a specific academic field have common styles and preferences for learning activities. By investigating three groups of students including science, management and social science students, it was found that science students were more uncomfortable to speak in groups or to give a presentation. In addition, science students preferred quiz and assignments as learning activities.

The study of Kalnishkan [1] indicates that computer science students share kinesthetic preference. That is they need concrete examples and learn by doing. Thus, the examples of preferred class activities for computer science students are laboratory sessions, field trips, experiment, and role playing.

Overall, there seems to be some evidence to indicate that apart from Thai culture, academic disciplines or study fields could influence the preference of students' learning approach and activities. Therefore, the lecturers should consider their students' disciplines in order to prepare suitable learning activities for them.

\section{Purpose of the study}

This study aims at identifying the preferred learning activities and the obstacles faced in a lecture class of students in the information technology department of Kasetsart University (Chalermphrakiat Sakon Nakhon Province Campus), Thailand. Consequently, the results should imply to an appropriate learning approach for the students.

\section{Research design}

This study was conducted by using questionnaires to answer the research questions. The interpretive case study employed content analysis to analyze the two open-ended questions asking about the preferred activities and problems faced in the lecture of Management Information Systems conducted during the second semester of 2013.

Content analysis was defined as "a research method for the subjective interpretation of the content of text data through the systematic classification process of coding and identifying themes or patterns" [8, p.1278] and "any qualitative data reduction and sense-making effort that takes a volume of qualitative material and attempts to identify core consistencies and meanings" [9, p.453]. It could be noticed that, from the definitions, content analysis could be a useful tool designed to help researchers understand social reality in a scientific manner. The purpose of content analysis is to identify themes or categorize the content and describe the social reality created by those themes or categories in a particular settings or phenomena [10].

Therefore, content analysis employed in this study to capture and explain the preference of learning activities and problems faced in a classroom of Thai students in a computer science related lecture.

\subsection{Sample}

The sample of the study consisted of 41 students in the Management Information Systems course. There were 16 male students $(39.02 \%)$ and 25 female students $(60.97 \%)$ studying in the Information Technology department, Faculty of Science and Engineering, Kasetsart University (Chalermphrakiat Sakon Nakhon Province Campus), Thailand in 2013.

\subsection{Gender}

Gender was found to have an impact on learning style and preference [11, 12, 13]. However, this study does not suggest separating gender in a classroom. Moreover, gender is a difficult factor to be controlled in any public university. In fact, it is better to allow each gender to learn from each other in the classroom. Additionally, the number of the responding male students does not significantly differ from the number of the responding female students. Thus, gender will be treated in this study as a control variable.

\subsection{Procedures}

The Data was collected during the second semester of 2013, and was analyzed by content analysis. Some codes were developed to categorize 
the data into themes. The results will be presented on Table 1 and Table 2 in the next section.

\section{Results}

In this section, the results are presented into tables: Table 1 and Table 2.

Table 1 presents frequency and percentage of the learning activities that students preferred. The results were categorized by using activity themes and were assigned leading roles. A list of some abbreviations and their meanings used for categorizing the answers is presented as following:
Activity themes:

$\begin{array}{ll}\text { LE } & \text { Lecture and Evaluation } \\ \text { DCS } & \text { Discussions } \\ \text { ETM } & \text { Entertainment }\end{array}$

Leading role:

LL Lecturers lead

SL Students lead

TGT Both lecturers and students work together

Lastly, Table 2 presents frequency and percentage of the problems that students faced in a class caused by their ability and the ability of their lecturers.

Table 1. Learning activities that students preferred.

\begin{tabular}{|l|l|c|c|c|}
\hline Themes & Learning activities & Leading role & Frequency & Percentage \\
\hline $\mathbf{1 . D C S}$ & & & $\mathbf{2 2}$ & $\mathbf{3 2 . 3 5 \%}$ \\
\hline & $\begin{array}{l}\text { Discussing on lecture } \\
\text { topics }\end{array}$ & TGT & 22 & $32.35 \%$ \\
\hline $\mathbf{2 . L E}$ & & & $\mathbf{3 4}$ & $\mathbf{5 0 . 0 0 \%}$ \\
\hline & Giving lecture & LL & 2 & $4.41 \%$ \\
\hline & $\begin{array}{l}\text { Lecturers summarize a } \\
\text { lesson taught in a class }\end{array}$ & LL & $2.94 \%$ \\
\hline & $\begin{array}{l}\text { Using multimedia as a } \\
\text { teaching tool }\end{array}$ & LL & 21 & $2.94 \%$ \\
\hline & $\begin{array}{l}\text { Asking questions to some } \\
\text { students }\end{array}$ & LL & 4 & $30.88 \%$ \\
\hline & Quiz & LL & $\mathbf{1 2}$ & $5.88 \%$ \\
\hline 3.ETM & Giving assignments & LL & 12 & $17.94 \%$ \\
\hline & $\begin{array}{l}\text { Having relaxing activities } \\
\text { such as talking about other } \\
\text { interesting and } \\
\text { encouraging areas rather } \\
\text { than lecture topics. }\end{array}$ & LL & & $\mathbf{1 7 . 6 5 \%}$ \\
\hline
\end{tabular}

Table 2. Problems that students faced in the class

\begin{tabular}{|l|c|c|}
\hline \multicolumn{1}{|c|}{ Problems } & Frequency & Percentage \\
\hline Students' ability & $\mathbf{3 1}$ & $\mathbf{7 3 . 8 1 \%}$ \\
\hline Students are too shy to ask questions in a class & 15 & $35.71 \%$ \\
\hline Students are a lack of enthusiasm to learn & 10 & $23.81 \%$ \\
\hline Students do not understand the lecture & 6 & $14.29 \%$ \\
\hline Lecturers' ability & $\mathbf{1 0}$ & $\mathbf{2 3 . 8 0 \%}$ \\
\hline Lecturers do not have a good teaching techniques & 5 & $11.90 \%$ \\
\hline $\begin{array}{l}\text { Lecturers do not give enough time to look after } \\
\text { each student }\end{array}$ & 2 & $4.76 \%$ \\
\hline $\begin{array}{l}\text { The class takes too long (one student said the } \\
\text { class that take longer than one hour and a half } \\
\text { without a break is too tiring.) }\end{array}$ & 3 & $7.14 \%$ \\
\hline Relationships between lecturers and students & $\mathbf{1}$ & $\mathbf{2 . 3 8 \%}$ \\
\hline Students do not feel familiar with the lecturers & 1 & $2.38 \%$ \\
\hline \multicolumn{1}{|c|}{ Total } & $\mathbf{4 2}$ & $\mathbf{1 0 0 \%}$ \\
\hline
\end{tabular}

*The percentage of numbers was rounded up. 


\section{Discussions}

The results (Table 1) show that most activities that Thai students in this case preferred are the activities led by lecturers (46 times mentioned by students out of 68 times which represents $67.65 \%$ of the total frequency) including 'lecture and evaluation' $50.00 \%$ (34 times mentioned by students) such as giving lectures and summarizing the lessons taught in a class, and 'entertainment' in a class $17.65 \%$ (12 times mentioned by students) such as talking about other interesting and encouraging areas rather the lecture topics, and going on excursions. In fact, there are no preferred activities led by students.

'Discussions' is the only activity that lecturers and students could equally put their efforts to work collaboratively. Additionally, discussing on lecture topics came out top of the preferred activities stated by students ( 22 times mentioned by students out of 68 times which represents $32.35 \%$ of the total frequency).

When look further into the theme of 'lecture and evaluation', it was found that quiz or scored tests in a class is the main method to assess learning in the Thai system. In this study, quiz is also one of the preferred activities apart from assignments. However, it was doubtful that using quiz was really a suitable assessment in a Thai classroom. Thus, the researcher asked students one more question for further clarification on whether giving a quiz as a main assessment is a suitable method or not. The majority of students (40 students out of 41 students which represent $97.56 \%$ of the total students) confirmed that a quiz or a scored test is a suitable method to assess their learning performance. Only one student suggested that a scored test should be used in conjunction with other practical methods such as assignments and projects. Quiz is a learning activity led by lecturers where lecturers have to put their efforts to determine an appropriate time limit, quiz format and number of quiz.

According to the problems that students faced in the class (Table 2), the results show that most of the problems are caused by student ability (31 times mentioned by students out of 42 times which represents $73.81 \%$ of the total frequency). The major problem is a lack of ability to cope with their fear or shyness to ask lecturers a question in a class when they do not understand a point (15 times mentioned by students out of 42 times which represents $35.71 \%$ of the total frequency). Moreover, students said they lacked enthusiasm to learn. Other problems are caused by limits of student capability such as a lack of the knowledge to understand a lecture and limits of lecturer capability such as a lack of the capability to teach and manage the time of a class.

Interestingly, it can be noticed from the results that a lack of desire to question a lecturer could be caused by the fact that students do not feel familiar with their lecturers. Therefore, the relationship between students and lecturers is quite important. To create a better learning environment, lecturers should lead a class with a friendly style.

Another important thing that can be noticed is students suggesting that lectures that last longer than one hour and a half make them exhausted and bored. Therefore, a break should be provided for students during a long period of study. Additionally, a deviation from the lecture topics should be included. The students suggested relaxing activities like talking about interesting and encouraging things apart from the course content, and creating some excursions as possible activities.

\section{Implications on learning approach}

The results obtained from the analysis indicate that the preferred learning activities and learning approach could be influenced by cultural background and a field of study. Moreover, some cultural aspects and some specific group characteristics of academic disciplines can lead to learning problems of students.

According to the preferred activities in a class, it can be seen that most preferred activities are led by lecturers. Lecturers play an important role in guiding the class. Therefore, a teacher-centered approach should be appropriate for Thai students as well as a discussion session to allow students to participate in a class. Thai students are likely to be influenced by academic disciplines and Thai culture to choose their learning approach.

The Thai culture mentioned above may influence Thai learning approach. In particular, the characteristics such as having authoritarian power and emotional value could lead to low selfconfidence and shyness, which in turn make Thai students reluctant to participate in a class.

In addition, the work of Chaidaroon [14] indicates that shyness is part of Thai cultural identity. Thais, when in some situations, are likely to conceal their feelings and keep silent. They hardly speak up, particularly in public. In some situations, Thai silence is not about shyness; it is a positive indication of respect [15] and being compromised. However, when in a classroom, shyness and silence could be obstacles to impede learning processes as can be identified from the results. The shyness could also be caused by students' disciplines since students in this study are computer science students. As described in the section 4 Academic disciplines and learning style, science students are likely to feel uncomfortable to speak in public or to give a presentation. However, they could do well on their own assignments. They like quiz and experiments.

Moreover, Thai culture has top-down centralized management in which Thais are expected to show obedience to their leaders (in a class context, leaders 
are lecturers). Hence, all control and decisions always depend on the leaders which are lecturers. In that regard, the relationship with leaders is very important and has an impact on student satisfaction [16]. Therefore, lecturers are suggested in this study to act like a moderator with friendliness to lead a class, to evaluate student performance by using quiz and to keep a warm relationship with their students to encourage participation in class and to achieve course objectives.

Apart from Thai culture, a field of study may also influence a preference in learning style and learning approach. The previous study [6,7], as mentioned above, shows that students in specific major academic disciplines have common preferences for learning styles and activities that assist the learning process since they process and perceive information differently. Students in scientific disciplines are not familiar with collaboration and are shy about revealing their feelings. In this study, the students studied a scientific discipline (Information technology) which influences students to prefer activities led by lecturers such as lecture and evaluation (i.e. quiz and assignment) because science students feel uncomfortable to speak in public and they learn by doing which makes them prefer doing tests and assignments.

With respect to the Thai preference of learning activity and a scientific disciplines mentioned above, the flipped learning model in which lecturers use technology to capture and record video lessons for their students to learn and prepare a class from home, then utilize class time to discuss homework and lessons with their fellow students [17], could be a supportive model to facilitate a teacher-centered approach in a Thai classroom. It allows lecturers managing their time with their students.

\section{Conclusions}

This study conducted a survey and employed content analysis to identify the preference of students in learning activity and to understand learning problems in a Thai computer science classroom.

It was suggested that Thai culture is likely to influence learning activity and approach. Therefore, the lecturer is the key person to lead a class with many roles such as delivering lecture, creating course content and objectives, evaluating students' learning performance, and facilitating students' learning with a teacher-centered approach. As the Thai students prefer discussions, some discussion sessions should be provided. In addition, the flipped learning model should be helpful to allow lecturers to manage quality and variety in their lecture. Furthermore, the academic fields of students should be considered when conducting and preparing learning activities to a class.

\section{Limitations and Future Work}

One should note that the results of this study are based on 41 students of the information technology department responding to a qualitative survey in a medium-sized university to gain a fundamental idea on the preferences of learning approach of Thai students. More research is needed to draw solid conclusions about the influencing factors on learning approach and learning performance (evaluated by test scores) including gender [11, 12, 13] and class size $[18,19]$. Of special interest would be similar research on extremely large samples of 300 or more students.

This study conducted a survey and employed content analysis to identify the preference of students in learning activity and to understand learning problems in a Thai computer science classroom.

\section{Acknowledgements}

The successful completion of this study was due to support provided by many people. In particular, I would like to thank for the faculty of Science and Engineering of Kasetsart University (Sakon Nakhon campus), Thailand for supporting and sponsoring this study.

\section{References}

[1] Y. Kalnishkan, Learning Style Models and Teaching of Computer Science, Department of Computer Science, University of London, 2009.

[2] T. Garrett, "Student-centered and teacher-centered classroom management: A case study of three elementary teachers", Journal of classroom Interaction, 43(1), 2008, pp. 34-47.

[3] G. Hofstede and G. Hofstede, Cultures and organizations, software of the mind, intercultural cooperation and its importance for survival, Revised and Expanded 2nd edition. New York: McGraw-Hill, 2005.

[4] R. M. Muller, "The influence of incentive and culture on knowledge sharing", Proceedings of the 38th Hawaii International Conference on System Sciences, Hawaii, USA, 2005.

[5] P. Numprasertchai and F. W. Swierczek, "Dimensions of Success in International Business Negotiations: A comparative study of Thai and international business negotiators", Journal of Intercultural Communication, 11, 2006.

[6] S.Tongkaw and B. Wood, "Group Characteristics and Learning Styles in Higher Education on Learning Management System", Proceeding of the the European Learning Styles, Information Network (ELSIN2009) 14th Annual Conference, Bulle-en-Gruyère, Switzerland,2009. 
[7] S.Tongkaw, Group characteristics and learning styles: an interpretive case study, Unpublished doctoral dissertation, University of Manchester, Manchester, United Kingdom, 2011.

[8] H.F.Hsieh and S.E. Shannon, "Three approaches to qualitative content analysis", Qualitative Health Research, 15 (9), 2005, pp.1277-1288.

[9] M.Q. Patton, Qualitative Research and Evaluation Methods, Thousand Oaks, CA: Sage.

[10] Y. Zhang and B.M. Wildemuth, Qualitative analysis of content, In B. Wildemuth (Ed.), Applications of Social Research Methods to Questions in Information and Library Science Westport, CT: Libraries Unlimited, 2009, pp.308319.

[11] S. Severiens and G. T. Dam, "Gender and Gender identity differences in learning styles.", Educational Psychology, 17 (1-2), 1997, pp. 79-93.

[12] R. Riding and M. Grimley, "cognitive style, gender and learning from multi-media materials in 11 years old children", British Journal of Educational Technology, 30(1), pp. 43-56.

[13] E.A. Wehrwein, H. L. Lujan and S. E. Dicarlo, "Gender differences in learning style preferences among undergraduate physiology students", Advances in Physiology Education, 31, 2007, pp. 153-157.

[14] S. S. Chaidaroon, "Effective communication management for Thai people", Proceeding of the Global Era international conference on Revising Globalization and Communication in the 2000s, Bangkok, Thailand, 2004.

[15] T. J. Knutson, Thailand as a laboratory for improved intercultural communication: Ethnographic, metaphoric, and social scientific implications, The meeting of the National Communication Association, Miami, FL, 2003.

[16] F.G. Adams and H. Vernon, "Economic developments, business culture and its links to business practice: Is there a Thai style of management?" International Journal of Business, 9(2), 2004.

[17] N. Hamdan, P. Mcknight, K. Mcknight and K. M. Arfstrom, "A review of flipped learning", Flipped learning network, 2013.

[18] J. D. Finn and C. M. Achilles, "Tennessee's class size study:findings, implications, misconceptions", Educational Evaluation and Policy Analysis, 21(2), pp.97-109.

[19] F. Karakaya, T. L. Ainscough and J. Chopoorian, "The effects of class size and learning style on student performance in a multimedia-based marketing course", Journal of Marketing Education, 2001. 